\title{
Stability of Fe-Cr Alloys in SOFC Fuel Atmosphere
}

\author{
Teruhisa HoRita, Haruo Kishimoto, \\ Katsuhiko YAMAJI, Yue-Ping XIONG, Natsuko SAKAI, \\ Manuel E. BRITO and Harumi YOKOKAWA \\ National Institute of Advanced Industrial Science and Technology, \\ AIST Central 5, 1-1-1, Higashi, Tsukuba-shi, \\ Ibaraki 305-8565, Japan
}

Keywords: Fe-Cr Alloy, Interconnects, Solid Oxide Fuel Cells, Oxide Scale

\begin{abstract}
The chemical stability of Fe-Cr alloys (ZMG232 and SUS430) was examined in fuel atmosphere of SOFC, especially in $\mathrm{H}_{2}-\mathrm{H}_{2} \mathrm{O}$ atmosphere. Oxide scales were formed on the alloy surface with a thickness of 3-5 $\mu \mathrm{m}$ at $1073 \mathrm{~K}$ for $1000 \mathrm{~h}$ by the diffusion of cations through the scale. The microstructures and elemental distribution of oxide scale/alloy interfaces were analyzed by the depth and surface analysis techniques: $\mathrm{Mn}-\mathrm{Cr}-(\mathrm{Fe})$ spinel, $\mathrm{Cr}_{2} \mathrm{O}_{3}$, and internal Si oxides were identified from surface to inner oxides. An anomalous thick oxide scale formation was found on SUS430 surface in $\mathrm{H}_{2}-\mathrm{H}_{2} \mathrm{O}$ atmospheres. A thick oxide scale was composed of $\mathrm{Fe}, \mathrm{Cr}$, and $\mathrm{Mn}$ oxides. A relatively high concentration of $\mathrm{Fe}$ was observed at top surface of oxide scale. The distribution of Si was found inside the oxide scale, suggesting an increase of oxygen potential and fast diffusion of Si inside the oxides. The formation of anomalous thick oxide scale can affect the stability of $\mathrm{Fe}-\mathrm{Cr}$ alloy interconnects by changing the cell connections at scale/alloy/cell interfaces.
\end{abstract}

\section{Introduction}

Alloy materials are promising candidates for interconnects of Solid Oxide Fuel Cells (SOFCs) operated at 873-1073 K (Anderson and Tietz 2003; Fergus, 2005). Important functions of alloy interconnects are the separation of fuel and air as well as electronic conduction with adjacent cells. During operation of SOFCs, the formation of protective oxide scale is inevitable on the alloy interconnect surface. This oxide scale is necessary to protect the alloys against vaporization of chromium and further oxidation. However, a thick oxide scale formation is not favorable in terms of the electrical conduction and the cell connections in SOFCs. Therefore, the oxide scales should have an optimum thickness and electronic conductivity during long-term operation.

Among several kinds of candidate alloys, $\mathrm{Fe}-\mathrm{Cr}$ alloys are one of the promising materials because of their cost and a relative stability (For example, Toji et al., 2005). The conventional $\mathrm{Fe}-\mathrm{Cr}$ alloys are stainless steel based alloys with $\mathrm{Cr}_{2} \mathrm{O}_{3}$ forming alloys. When $\mathrm{Mn}$ is added into $\mathrm{Fe}-\mathrm{Cr}$ alloy, the oxide scales can have the following phases from surface: $\mathrm{Cr}-\mathrm{Mn}-(\mathrm{Fe})$ spinel,

Received on May 15, 2007; accepted on July 12, 2007. Correspondence concerning this article should be addressed to T. Horita (E-mail address: t.horita@aist.go.jp).

Presented at International Symposium on Innovative Materials for Processes in Energy Systems, IMPRES, Kyoto, October, 2007.
$\mathrm{Cr}_{2} \mathrm{O}_{3}$ based oxide, and internal oxides. The top surface of $\mathrm{Cr}-\mathrm{Mn}$ spinel can reduce the activity of $\mathrm{Cr}$ vapor and have the higher electrical conductivity. The oxide scale formation occurs in an air atmosphere. Even in fuel atmospheres, oxide scales were formed in similar phases and structures due to $\mathrm{H}_{2} \mathrm{O}$ (Horita et al., 2003). However, the oxidation rates and the electrical conduction of oxidized alloys were somewhat different from atmospheres and $\mathrm{Fe}-\mathrm{Cr}$ alloy materials. This can be related to the difference of cation diffusivity in the oxide scale and mass transports of minor elements in the $\mathrm{Fe}-\mathrm{Cr}$ alloys (such as $\mathrm{Si}$ and $\mathrm{Al}$ ). In some cases under SOFC operation, an "anomalous" thick oxide scale formation was reported by several authors (Yang et al., 2004; Kameda et al., 2005; Sakai et al., 2005). The formation of cation vacancies in the oxide scale can affect the stability of alloys by the formation of thick oxide scales. Also, glass-sealing materials can affect the stability of oxide scales because of the reaction of glass elements with $\mathrm{Cr}_{2} \mathrm{O}_{3}$ protective oxide scales.

The purpose of the present study is to clarify the stability of $\mathrm{Fe}-\mathrm{Cr}$ alloy and its oxide scales in fuel atmosphere of SOFC. Especially in this report, the formation of oxide scales is compared between two different $\mathrm{Fe}-\mathrm{Cr}$ alloys in $\mathrm{H}_{2}-\mathrm{H}_{2} \mathrm{O}$ atmosphere: ZMG232 and SUS430. Also, the formation of an anomalous thick oxide scale formation is discussed based on the mass transports in the oxide scales. 
Table 1 Chemical compositions of $\mathrm{Fe}-\mathrm{Cr}$ alloys examined for oxidation analysis (Figures are in mass \%)

\begin{tabular}{lcc}
\hline & $\begin{array}{c}\text { ZMG232 } \\
\text { (Hitachi Metals Ltd.) }\end{array}$ & $\begin{array}{c}\text { SUS430 } \\
\text { (Purchased from Nilaco Co.) }\end{array}$ \\
\hline $\mathrm{C}$ & 0.02 & 0.048 \\
$\mathrm{Si}$ & 0.40 & 0.35 \\
$\mathrm{Mn}$ & 0.50 & 0.21 \\
$\mathrm{Ni}$ & 0.26 & 0.12 \\
$\mathrm{Cr}$ & 21.97 & 16.35 \\
$\mathrm{Al}$ & 0.21 & 0.05 \\
$\mathrm{Zr}$ & 0.22 & - \\
$\mathrm{La}$ & 0.04 & - \\
$\mathrm{Fe}$ & 76.38 & 82.87 \\
\hline
\end{tabular}

\section{Experimental}

\subsection{Materials}

Test samples examined were $\mathrm{Fe}-\mathrm{Cr}$ alloys which have about 16-22 mass\% of $\mathrm{Cr}$ (ZMG232 and SUS430). The chemical composition of the alloy is listed in Table 1. There is some minor elements addition into $\mathrm{Fe}-\mathrm{Cr}$ alloys, which increases the oxidant resistance in ZMG232. The samples surface was polished by a diamond paste to obtain flat and smooth plane to analyze the oxide scale formation at oxide scale/alloy interfaces.

\subsection{Oxidation experiments}

The oxide scale formation was examined in $\mathrm{H}_{2}-$ $\mathrm{H}_{2} \mathrm{O}$ mixtures at $1073 \mathrm{~K}$ for more than $1000 \mathrm{~h}$. The partial pressure of $\mathrm{H}_{2}$ and $\mathrm{Ar}$ was set as $p\left(\mathrm{H}_{2}\right) / p(\mathrm{Ar})=$ $0.09 / 0.80$ bar with $p\left(\mathrm{H}_{2} \mathrm{O}\right)=0.11$ bar. The calculated oxygen partial pressure is estimated to be $1.5 \times 10^{-17}$ bar. At this oxygen partial pressure, $\mathrm{Cr}_{2} \mathrm{O}_{3}$ can be formed on $\mathrm{Fe}-\mathrm{Cr}$ alloy surface from the equilibrium calculation.

\subsection{Analysis of oxide scale/alloy interfaces}

The microstructures and elemental distribution at oxide scale/alloy interfaces were analyzed by scanning electron microscopy (SEM) (VE-7800, KEYENCE Corp.) with EDX (Kevex) The depth profiles of elements from sample surface were analyzed by Glow Discharge Optical Emission Spectroscopy (GDOES, JY-5000RF, Jobin Yvon/HORIBA). The elemental distribution of minor elements around the oxide scale/alloy interface was analyzed by Secondary Ion Mass Spectrometry (SIMS, CAMECA-ims 5f).

\section{Results and Discussion}

\subsection{Surface microstructures of oxide scales}

The surface microstructure of oxide scale was investigated for two different $\mathrm{Fe}-\mathrm{Cr}$ alloys: ZMG232 and SUS430. Figure 1 shows surface microstructure of oxidized ZMG232 and SUS430 in $\mathrm{H}_{2}-\mathrm{H}_{2} \mathrm{O}$ at $1073 \mathrm{~K}$ for $72 \mathrm{~h}$. Small grains of oxide scales were formed on the oxide scale surface with height difference of sub-
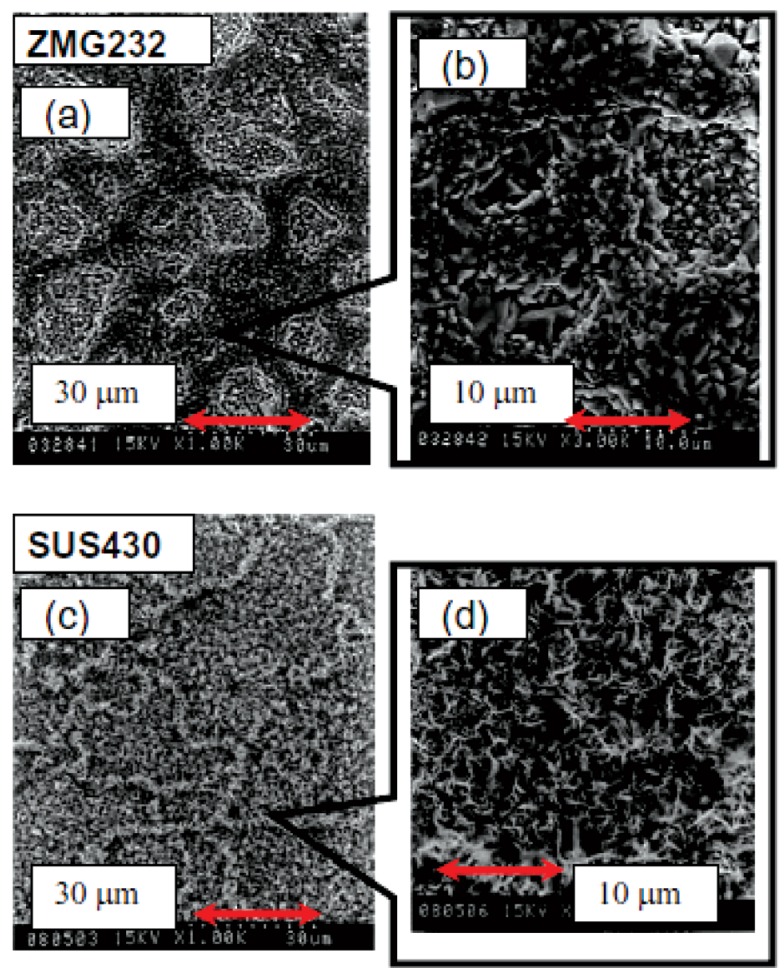

Fig. 1 Surface microstructures of oxidized alloys (annealed at $1073 \mathrm{~K}$ for $72 \mathrm{~h}$ in $\mathrm{H}_{2}-\mathrm{H}_{2} \mathrm{O}$ ). (a) SEM image of oxidized ZMG232; (b) high magnification image of (a); (c) SEM image of oxidized SUS430; (d) high magnification image of (c)

$\mu \mathrm{m}$ level on both alloys. The grain boundaries of alloy parts show relatively the higher heights, and these parts are considered to be the initial oxidation parts on both $\mathrm{Fe}-\mathrm{Cr}$ alloys. Thus, the oxide scale formation mechanism is considered to be similar at the initial oxidation between ZMG232 and SUS430.

\subsection{Cross section of oxide scale/alloy interfaces}

The microstructures of cross section were examined at oxide scale/alloy interfaces. Figure 2 shows microstructures of cross section at oxide scale/alloy interfaces in $\mathrm{H}_{2}-\mathrm{H}_{2} \mathrm{O}$ for ZMG232 (Figure 2(a)) and SUS430 (Figures 2(b) and (c)) after oxidation at $1073 \mathrm{~K}$ for about $1050 \mathrm{~h}$. The oxide scales are identified as gray zone on the alloy surface. Black parts at the interfaces are considered to be $\mathrm{SiO}_{2}$ internal oxides in Figure 2(a). The oxide scale thickness is about $3.8-4.5 \mu \mathrm{m}$, which is a little bit different from the alloys (ZMG232 shows the thinner oxide scales). In the case of SUS430 alloy (Figure 2(b)), clean oxide scale/ alloy interface is observed. However, black lines were sometimes observed at the interfaces (Figure 2(c)). Since the thickness of the scale is similar between Figure 2(b) and Figure 2(c), the oxide scales were considered to be broken during preparing the samples. This indicates that the mechanical strength or the adhesion of oxide scale is not strong enough in SUS430 alloy. 


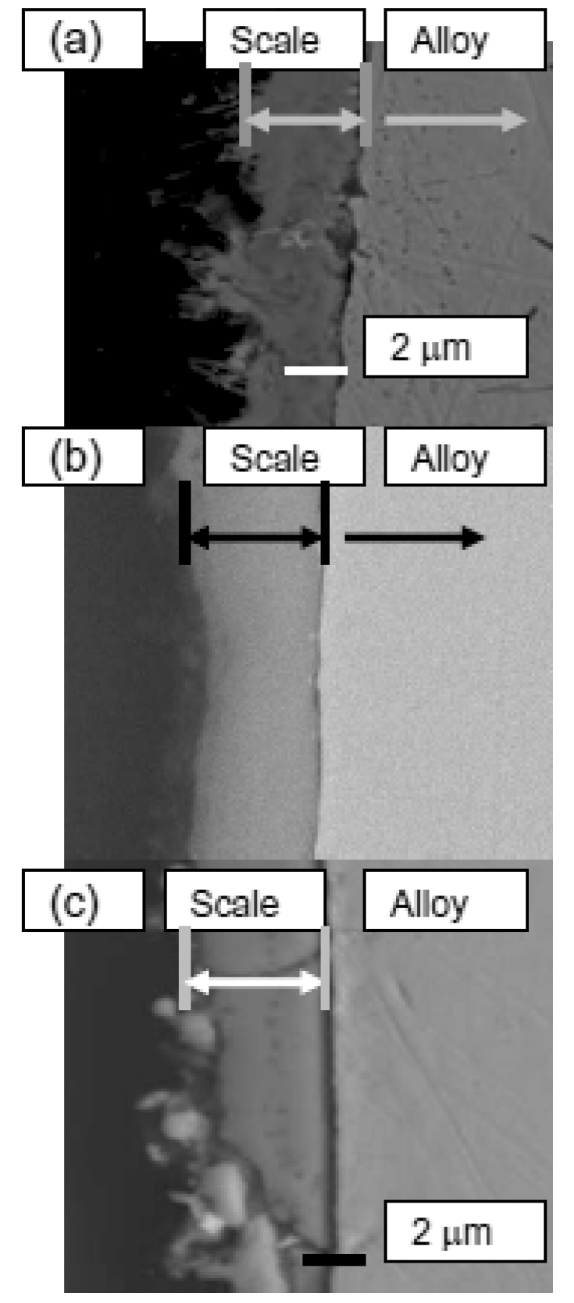

Fig. 2 SEM images of oxide scale/alloy interfaces (in $\mathrm{H}_{2}-\mathrm{H}_{2} \mathrm{O}$ at $1073 \mathrm{~K}$ for $1050 \mathrm{~h}$ ): (a) ZMG232; (b) SUS430; (c) SUS430 (detached part)

\subsection{Elemental distribution around the oxide scale/} alloy interfaces

The elemental distribution was examined at oxide scale/alloy interfaces. Figure 3 shows depth profiles of elements around the oxide scale/alloy interfaces measured by GDOES. The $y$-axis indicates the optical intensity for each element, which is proportional to the concentration and sputtering rates. Thus, we assume this parameter for estimating the concentration of elements at a constant sputtering rate. The oxide scale is composed of Mn-rich surface area, $\mathrm{Cr}$-rich part, and $\mathrm{Si}$-rich scale/alloy interface. In the case of ZMG232 (Figure 3(a)), high concentration of $\mathrm{Fe}$ is identified at the top surface of oxide scale. A relatively high concentration of $\mathrm{Si}$ is observed at the oxide scale/ alloy interfaces for both alloys (in Figure 3). This $\mathrm{Si}$ is considered to be $\mathrm{SiO}_{2}$ precipitated and condensed at the interfaces, not in the oxide sale. Al-internal oxide is observed inside the alloy. The oxide scale thickness

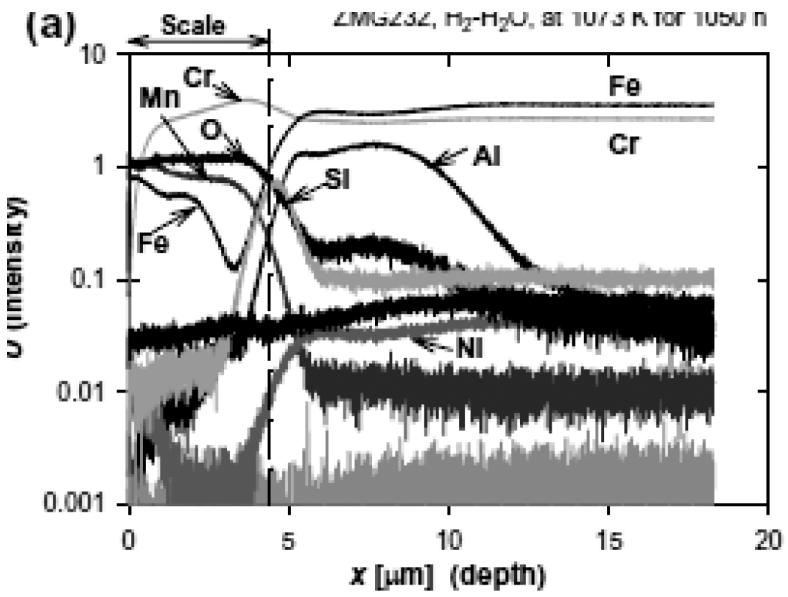

(b)

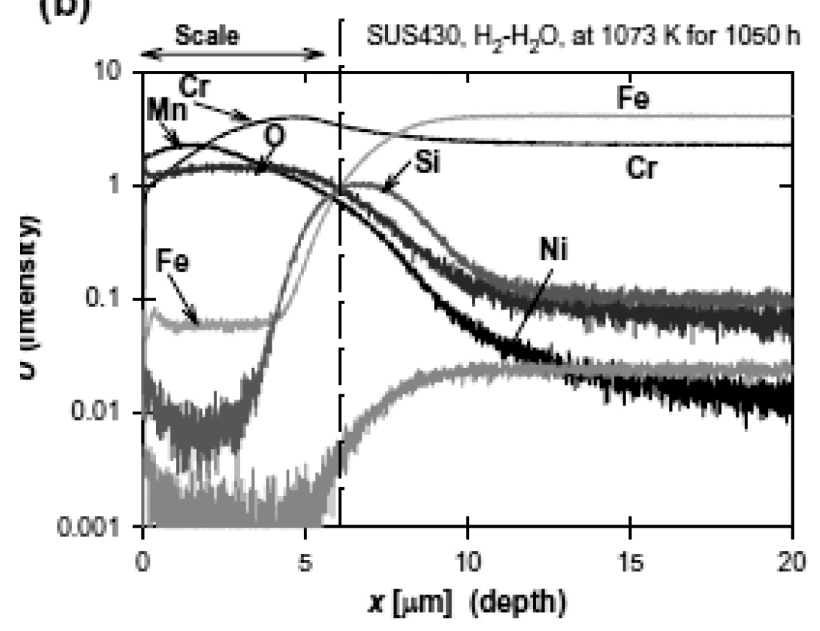

Fig. 3 GDOES depth profiles at oxide scale/alloy interfaces: (a) GDOES profiles of oxidized ZMG232 (at $1073 \mathrm{~K}$ for $1050 \mathrm{~h}$ ); (b) GDOES profiles of oxidized SUS430 (at $1073 \mathrm{~K}$ for $1050 \mathrm{~h}$ )

is a little bit thinner in ZMG232 from the profiles of O. The difference of elemental distribution can affect the scale stability and adhesion of scale on alloys.

From the GDOES depth profile analysis, the oxide scale thickness was estimated in the flat part of depth profiles of $\mathrm{O}$ (also, the thickness of oxide scale was checked in the SEM images). Figure 4 shows oxide scale thickness of ZMG232 and SUS 430 as a function of annealing time at $1073 \mathrm{~K}$. The scale thickness increases with time in a parabolic relationship. That is, the square of scale thickness increases with time in the following relationship;

$$
x^{2}=k_{p} t
$$

where $x$ is the thickness of oxide scale from the GDOES depth profiles, $t$ is annealing time, and $k_{p}$ is the oxide scale growth rate constant. This suggests that the growth of oxide scale is controlled by the diffusion 


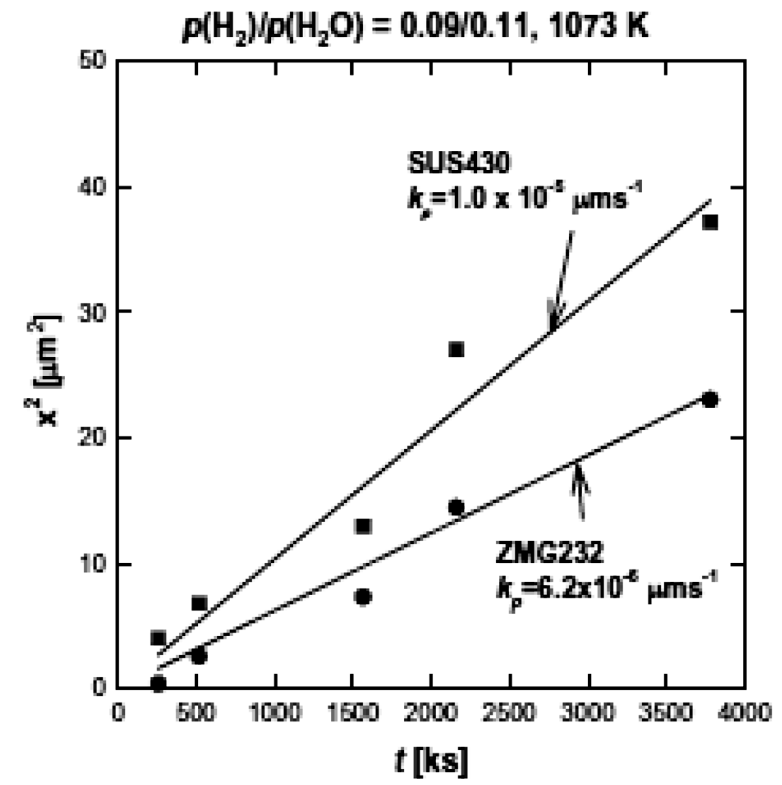

Fig. 4 Oxide scale thickness for two different alloys as a function of annealing time

process, such as diffusion of cation through the oxide scales. The $k_{p}$ value was estimated from the slopes of the plots in Figure 4 . The obtained $k_{p}$ values for ZMG232 and SUS430 are $6.2 \times 10^{-6} \mu \mathrm{m}^{2} \mathrm{~s}^{-1}$ and $1.0 \times$ $10^{-5} \mu \mathrm{m}^{2} \mathrm{~s}^{-1}$, respectively. Thus, ZMG232 has the higher oxidant resistance than SUS430. The difference of growth rate constants can come from the diffusivity of cations through the oxide scales. Although some differences were observed on the oxide scale growth rates between ZMG232 and SUS430, the growth mechanism is considered to be diffusion-controlled of cations through the oxide scales. This "normal oxide scales" show the thickness of 3-6 $\mu \mathrm{m}$ after oxidation for $1000 \mathrm{~h}$ at $1073 \mathrm{~K}$.

\subsection{Anomalous thick oxide scale formation in $\mathrm{H}_{2}-$ $\mathrm{H}_{2} \mathrm{O}$}

A thick oxide scale was occasionally observed on one side of alloy surface annealed in $\mathrm{H}_{2}-\mathrm{H}_{2} \mathrm{O}$ atmosphere. Figure 5 shows an example of microstructures for anomalous thick oxide scale formed on SUS430 alloy surface. The thickness of oxide scale is about $10-13 \mu \mathrm{m}$, which is $2-4$ times thicker than the normal oxide scale. The oxide scale has almost no voids but cracks. Therefore, an anomalous oxide scale formation can be related to the fast diffusion of cations through the oxide scale. Some cracks of oxide scale are thought to be formed during sample preparation, such as polishing and cutting. However, the mechanical strength of oxide scale on SUS430 is considered to be smaller than that of normal scale on ZMG232, and this can be related to the stability and scale adhesion on the alloy surface. The formation of anomalous thick oxide scale did not follow the diffusion controlled oxide scale

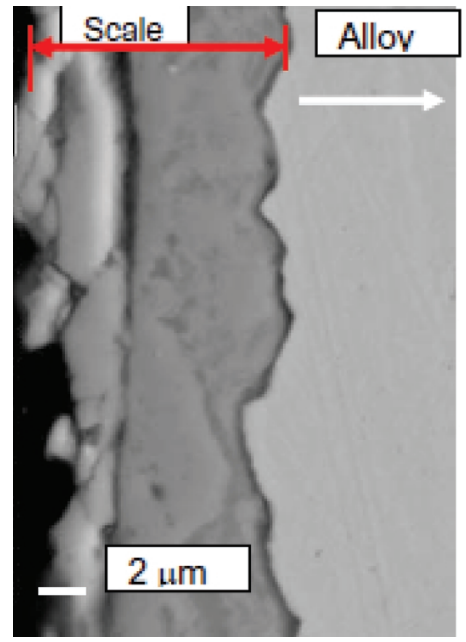

Fig. 5 SEM images of anomalous thick oxide scale/alloy interface (oxidation at $1073 \mathrm{~K}$ for $1050 \mathrm{~h}$ )

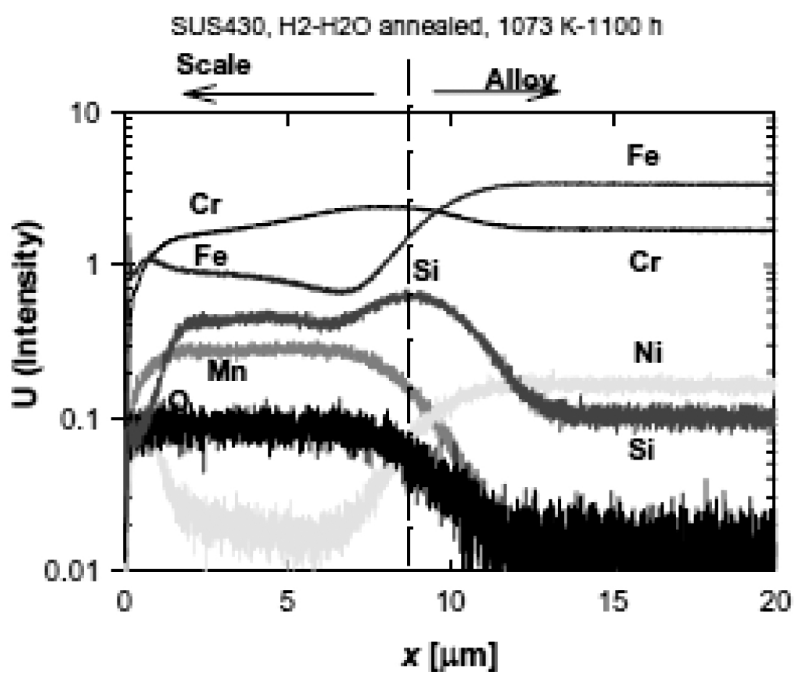

Fig. 6 GDOES depth profiles at anomalous oxide scale/ alloy interfaces (oxidation at $1073 \mathrm{~K}$ for $1050 \mathrm{~h}$ )

mechanism as was observed in the previous section (Figure 4).

The elemental distribution of this part was investigated by GDOES depth profiles (Figure 6). The oxide scale is composed of Fe-rich surface, $\mathrm{Mn}$ and $\mathrm{Cr}$ rich intermediate part, and $\mathrm{Si}$ rich oxide scale/alloy interface. Relatively high signal counts of $\mathrm{Si}$ are observed at the oxide scale part, suggesting high diffusivity and reaction of $\mathrm{Si}$ inside the oxide scale. A relatively high signal count of $\mathrm{Fe}$ is observed at the top surface of oxide scale, suggesting a fast diffusion of Fe through the scale. From XRD analysis, $\mathrm{Fe}_{2} \mathrm{O}_{3}$ phase was also identified at the top surface, which confirms the anomalous diffusion of Fe. The elemental distribution of anomalous thick oxide scale is completely different from that of normal oxide scale: the existence 


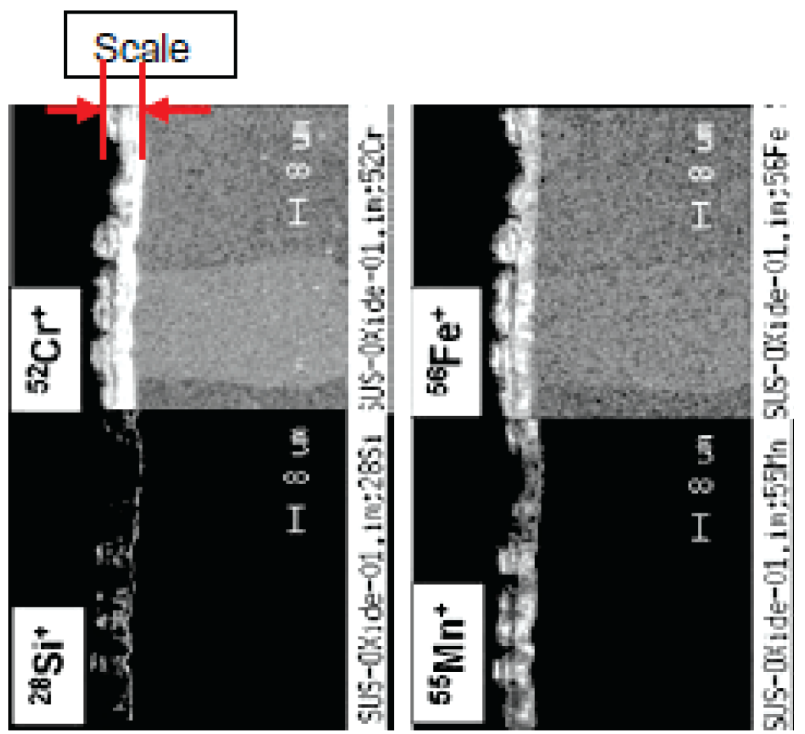

Fig. 7 SIMS images of each secondary ion at anomalous oxide scale/alloy interfaces (Oxidation at $1073 \mathrm{~K}$ for $1050 \mathrm{~h}$ )

of $\mathrm{Si}$ and $\mathrm{Fe}$ in the oxide scales can be related to the formation of anomalous thick oxide scales.

To investigate the elemental distribution of anomalous oxide more precisely, SIMS imaging analysis was examined at the anomalous oxide scale/alloy interfaces (Figure 7). The SIMS images show that the oxide scale is composed of $\mathrm{Cr}, \mathrm{Mn}$, and $\mathrm{Fe}$, which is considered to be $\mathrm{Fe}_{2} \mathrm{O}_{3}, \mathrm{Fe}-\mathrm{Cr}-\mathrm{Mn}$-spinel and $\mathrm{Cr}_{2} \mathrm{O}_{3}$ from the X-ray diffraction analysis. The most surprising thing is the distribution of $\mathrm{Si}$, as indicated in GDOES depth profiles: relatively high signal counts of $\mathrm{Si}$ are observed inside the oxide scale as well as the oxide scale/alloy interface. This distribution of Si is completely different from the normal oxide scale. The concentration of $\mathrm{Si}$ is not homogenously distributed inside the oxide scale, which suggests the difference of diffusivity and reactivity of $\mathrm{Si}$ from the positions of the oxide scale. The grain boundaries of oxide scale can be related to this phenomenon.

In terms of oxide scale stability, a thick oxide scale formation is not favorable because of the break down of protective oxides layers. The break down of protective oxide scale can increase the thickness of oxide scale, which deteriorates the electrical conductivity. The $\mathrm{Fe}-\mathrm{Cr}-\mathrm{Mn}$ spinel oxide is replaced by $\mathrm{Fe}_{2} \mathrm{O}_{3}$ based oxide at the top surface of oxide scale. The formation mechanism of such a thick anomalous oxide scale is under consideration. One possibility is the reaction of $\mathrm{MnFe}_{2} \mathrm{O}_{4}$ spinel with $\mathrm{SiO}_{2}$ (from impurity in the gas phase, such as from $\mathrm{Al}_{2} \mathrm{O}_{3}$ tube); this reaction altered the diffusivity of cations inside the oxide scales since the cation diffusivity is significantly changed by the substitution of cations in $\mathrm{M}_{3} \mathrm{O}_{4}$ (M: metals) as follows:

$$
\begin{aligned}
& 3 \mathrm{MnFe}_{2} \mathrm{O}_{4}+3 / 2 \mathrm{SiO}_{2} \\
& =2 \mathrm{Fe}_{3} \mathrm{O}_{4}+3 / 2 \mathrm{Mn}_{2} \mathrm{SiO}_{4}+1 / 2 \mathrm{O}_{2}
\end{aligned}
$$

The formation of $\mathrm{Fe}_{3} \mathrm{O}_{4}$ increases the diffusion coefficient of $\mathrm{Fe}$ in the oxide more than 100 times that in $\mathrm{MnFe}_{2} \mathrm{O}_{4}$. The higher diffusivity of Fe generates the thicker oxide scales than the normal one. We will report further results in the future. In any reasons for the formation of anomalous thick oxide scales, they affect the stability of $\mathrm{Fe}-\mathrm{Cr}$ alloy in terms of connections at oxide scale/alloy/cell interfaces.

\section{Conclusions}

The chemical stability of $\mathrm{Fe}-\mathrm{Cr}$ alloys was examined in $\mathrm{H}_{2}-\mathrm{H}_{2} \mathrm{O}$ atmosphere for SOFCs. The oxide scales were formed on the alloy surface with a thickness of 3-6 $\mu \mathrm{m}$ at $1073 \mathrm{~K}$ for more than $1000 \mathrm{~h}$. The diffusion controlled mechanism was assumed for the normal oxide scales, in which the cation diffusion through the scale is rate-determining for oxide scale growth. The microstructures and elemental distribution of oxide scale/alloy interfaces were analyzed by depth analysis and surface analysis techniques: Mn$\mathrm{Cr}-(\mathrm{Fe})$ spinel, $\mathrm{Cr}_{2} \mathrm{O}_{3}$, and internal $\mathrm{Si}$ oxides were formed from surface to inner oxides. An anomalous thick oxide scale formation was found on SUS430 surface in $\mathrm{H}_{2}-\mathrm{H}_{2} \mathrm{O}$ atmospheres. A thick oxide scale was composed of $\mathrm{Fe}, \mathrm{Cr}, \mathrm{Mn}$ oxides. Relatively high concentration of $\mathrm{Fe}$ and $\mathrm{Si}$ were observed at surface and inside the oxide scale, suggesting a fast diffusivity of cations inside the oxides. The formation of anomalous thick oxide scale can affect the stability of $\mathrm{Fe}-\mathrm{Cr}$ alloy interconnects by changing the cell connections at scale/alloy/cell interfaces.

\section{Literature Cited}

Anderson, H. U. and F. Tietz; "Interconnects," High Temperature Solid Oxide Fuel Cells, pp. 173-195, S. C. Singhal and K. Kendall eds., Elsevier, Oxford, U.K. (2003)

Fergus, J. W.; "Metallic Iinterconnects for Solid Oxide Fuel Cells," Mater. Sci. Eng., A, 397 271-283 (2005)

Horita, T., Y. Xiong, K. Yamaji, N. Sakai and H. Yokokawa; "Evaluation of $\mathrm{Fe}-\mathrm{Cr}$ Alloys as Interconnects for Reduced Operation Temperature SOFCs," J. Electrochem. Soc., 150, A243-A248 (2003)

Kameda, H., K. Ogasawara, Y. Matsuzaki, T. Sakurai, T. Uehara, A. Toji, N. Sakai, K. Yamaji, T. Horita and H. Yokokawa; "Stability of Alloy Interconnect for SOFCs: Prevention of Initial Degradation," Extended Abstract of The 14th Symposium on Solid Oxide Fuel Cells in Japan, pp. 180-182, Tokyo, Japan (2005)

Sakai, N., K. Yamaji, T. Horita, H. Yokokawa, T. Uehara, A. Toji, H. Kameda, K. Ogasawara, Y. Matsuzaki and T. Sakurai; "Stability of Alloy Interconnect for SOFCs: Reactivity with Sealing Materials," Extended Abstract of The 14th Symposium on Solid Oxide Fuel Cells in Japan, pp. 142-144, Tokyo, Japan (2005)

Toji, A., T. Uehara and T. Ohno; "Effect of Alloying Elements on Properties of Ferritic Fe-Cr Alloys for SOFC Interconnects," 
Solid Oxide Fuel Cells IX, PV2005-07, pp. 1789-1794, S. C. Singhal and J. Mizusaki eds., Pennington, U.S.A. (2005)

Yang, Z., M. S. Walker, P. Singh, J. W. Stevenson and T. Norby;
"Oxidation Behavior of Ferritic Stainless Steels under SOFC Interconnect Exposure Conditions," J. Electrochem. Soc., 151, B669-B678 (2004) 